\title{
Northern Hemisphere summer temperature and specific humidity anomalies from two reanalyses
}

\author{
Emily C. Gill, ${ }^{1,2}$ Thomas N. Chase, ${ }^{1}$ Roger A. Pielke Sr., ${ }^{1,3}$ and Klaus Wolter ${ }^{1,4}$ \\ Received 1 February 2013; revised 3 July 2013; accepted 8 July 2013.
}

[1] This study investigates the magnitude and spatial extent of extreme summer temperature and specific humidity events in the extratropical northern hemisphere (NHEXT) using the NCEP Reanalysis (1979-2012) and the $20^{\text {th }}$ century reanalysis (1871-2010). Specifically, we look at the percentage of area exceeding standard deviation thresholds in layer-averaged $(500 \mathrm{mb}-1000 \mathrm{mb})$ temperature and surface-level specific humidity to classify extremes. We find that: (1) areas of the NHEXT, including the southwestern tip of Greenland, experienced a summer heat wave during 2012 that was almost as extreme in spatial extent and magnitude as the Russian heat wave of 2010, (2) there is an increasing trend in summer heat waves and positive specific humidity anomalies and a decreasing trend in summer cold waves and negative specific humidity anomalies, and (3) while similar patterns in the global trend (1979-2012) in variability exist for both temperature and specific humidity, areas of increased variability are not necessarily the areas that have experienced extreme heat waves.

Citation: Gill, E. C., T. N. Chase, R. A. Pielke Sr., and K. Wolter (2013), Northern Hemisphere summer temperature and specific humidity anomalies from two reanalyses, J. Geophys. Res. Atmos., 118, doi:10.1002/jgrd.50635.

\section{Introduction}

[2] Increased concentrations of greenhouse gases increase downwelling infrared radiation, resulting in strong heating at the Earth's surface. Of the total greenhouse effect, Schmidt et al. [2010] found that water vapor, clouds, and $\mathrm{CO}_{2}$ are the major contributors accounting for approximately 50\%, 25\%, and $20 \%$, respectively, of all long-wave absorption in the atmosphere. Warming of the planet, particularly at lower latitudes where ocean temperatures are the warmest, would increase concentrations of water vapor, the most powerful greenhouse gas, by exponentially increasing the moistureholding capacity of the atmosphere allowing for higher evaporation [Schneider et al., 1999; Held and Soden, 2000; Khon et al., 2010; Sun et al., 2009], while also increasing the residence time of atmospheric water vapor [Trenberth, 1998, 1999]. This positive water vapor feedback is one of the most powerful feedbacks in our climate system: with most

Additional supporting information may be found in the online version of this article.

${ }^{1}$ Cooperative Institute for Research in Environmental Science, University of Colorado Boulder, Boulder, Colorado, USA.

${ }^{2}$ Hydrology, Water Resources, and Environmental Fluid Mechanics, Civil Engineering, University of Colorado Boulder, Boulder, Colorado, USA.

${ }^{3}$ Atmospheric and Oceanic Sciences, University of Colorado Boulder, Boulder, Colorado, USA.

${ }^{4}$ Physical Sciences Division, ESRL, NOAA, Boulder, Colorado, USA.

Corresponding author: E. C. Gill, Cooperative Institute for Research in Environmental Science, University of Colorado Boulder, UCB 216 , Boulder, CO 80309-0216, USA. (emily.gill@colorado.edu)

(C)2013. American Geophysical Union. All Rights Reserved. 2169-897X/13/10.1002/jgrd.50635 research supporting a magnitude of 1.5 to $2.0 \mathrm{~W} / \mathrm{m}^{2} / \mathrm{K}$ [Dessler and Sherwood, 2009], it has the capacity to double the warming from carbon dioxide [Randall et al., 2007]. In regards to observed trends, Santer et al. [2007] found an increasing trend $\left(0.4 \mathrm{~kg} / \mathrm{m}^{2} /\right.$ decade $)$ in total atmospheric moisture content since 1988, while Vonder Haar et al. [2012] found no upwards or downwards trend in annual global water vapor.

[3] An intensification of the hydrological cycle induced by an increase in greenhouse gases has been predicted [Trenberth, 1998, 1999; Allen and Ingram, 2002; Held and Soden, 2006; Wentz et al., 2007] and shown [Willett et al., 2007; Durack et al., 2012]. It is predicted that wet and dry latitudes will become wetter and drier, respectively, which is consistent with model findings [Allen and Ingram, 2002; Emori and Brown, 2005] and recent observational findings of lower ocean salinity along latitudes with greater precipitation [Durack et al., 2012] and vice versa. As of 2011, the five most extreme summer heat waves to hit Europe since 1871 have all occurred within the past decade [Barriopedro et al., 2011], with the 2010 Russian heat wave being the most extreme. It is reasonable to assume that the recent occurrence of extreme summer heat waves could be accounted for by a shift towards higher variability and/or a shift in the mean. Donat and Alexander [2012] found that between two 30 year periods (1951-1980 and 1981-2010), probability distributions of both daily maximum and daily minimum temperature shifted and skewed significantly higher in all regions, concluding that global temperature variability has become more extreme since the mid- $20^{\text {th }}$ century. With regard to the 2010 heat wave, Dole et al. [2011] concluded it was mainly due to natural internal atmospheric variability, while 
Rahmstorf and Coumou [2011] claim it was $80 \%$ more likely to have occurred due to increased variability associated with global warming.

[4] In a previous paper on the 2003 European heat wave [Chase et al., 2006], we did not find a significant upward trend in the coverage of extreme summer temperature anomalies; thus, we feel that the time is ripe to update and extend our analysis. We aim to investigate the following questions with respect to the lower half of the troposphere: (1) how often have predefined thresholds been exceeded for positive and negative temperature and water vapor anomalies?, (2) are there any trends in summers with extreme temperature and/or water vapor over time?, (3) are there spatial and/or temporal correlations between temperature and water vapor trends?, (4) how has regional variability in both temperature and atmospheric water vapor changed over time?, and (5) are the areas experiencing increasing variability also the areas experiencing extreme temperature? We expect to see areas experiencing temperature extremes to be simultaneously experiencing specific humidity extremes.

[5] This study utilizes two reanalyses: the National Centers for Environmental Protection and National Center for Atmospheric Research Global Reanalysis (NCEP Reanalysis) [Kalnay et al., 1996] and the National Oceanic and Atmospheric Administration (NOAA) 20th Century Reanalysis [Compo et al., 2011]. While the NCEP Reanalysis extends from present back to 1948 , discontinuities in the time series exist when satellite data were assimilated after 1979. Therefore, we limit our analysis of the NCEP Reanalysis to the more recent time period of 1979-2012. The $20^{\text {th }}$ century reanalysis was developed in an effort to accurately cover a longer time period by assimilating only surface observations of pressure, monthly sea surface temperature and sea ice distribution, hence providing this study with a longer data set for comparison with the NCEP reanalysis. Details on the accuracy and development of this data set can be found in Compo et al. [2011], as well as in the supplemental documents of this paper (Figures 7-10). The majority of ocean surface-level pressure measurements were obtained from ICOADS (coverage is documented at http://icoads. noaa.gov/r2.5slp.html).

[6] We assess Northern Hemisphere summer (June, July, and August, JJA) temperature and specific humidity anomalies and trends from (1871 to 2012 for $20^{\text {th }}$ century reanalysis with $2^{\circ} \times 2^{\circ}$ resolution; 1979 to 2012 for NCEP Reanalysis with $2.5^{\circ} \times 2.5^{\circ}$ resolution) for the extratropical northern hemisphere, (NHEXT). We utilize monthly mean data derived from 6 hour subdaily values by NCEP. We define the NHEXT region as $22-80^{\circ} \mathrm{N}$ due to the sparse distribution of observations in higher latitudes and the limited yearly variability in the tropics. We chose to include the entire globe in Figures 2 and 6 to provide context; however, all histograms (Figures 1, 3-5) are specific to the defined NHEXT region.

[7] The NCEP/NCAR global reanalysis has been used in the past to investigate global and regional tropospheric temperature trends [Chase et al., 2000, 2006, 2008]. This study uses methods similar to Chase et al. [2000, 2006, 2008] to investigate lower tropospheric summer temperature and surface-level specific humidity anomalies and trends since 1979. We use surface-level specific humidity due to known [Paltridge et al., 2009; Dessler and Davis, 2010] spurious negative trends in specific humidity at higher altitudes and the overall lack of vapor at $500 \mathrm{mb}$. Temperature data were derived from geopotential thickness using,

$$
T=\frac{\left[\Phi\left(p_{2}\right)-\Phi\left(p_{1}\right)\right] \cdot g \cdot \log \left(\frac{p_{1}}{p_{2}}\right)}{R_{d}}
$$

where $T$ is the derived temperature $(\mathrm{K}), \Phi\left(p_{1}\right)$ is the geopotential height at the lower pressure level, $\Phi\left(h_{2}\right)$ is the geopotential height at the upper pressure level, $g$ is the gravitational constant $\left(9.81 \frac{\mathrm{m}}{\mathrm{s}^{2}}\right)$, and $R_{d}$ is the gas constant for dry air $\left(287 \frac{\mathrm{J}}{\mathrm{kg} \cdot \mathrm{K}}\right)$. This method is used to derive the layer-averaged temperatures between an upper pressure level of $500 \mathrm{mb}$ and a lower pressure level of $1000 \mathrm{mb}$. We chose to use thickness temperature derived from geopotential height to: (1) stay consistent with previous similar studies, and (2) reduce noise by using a vertical average through the lower troposphere, acknowledging that this is a meteorologically significant region in considering atmospheric warming.

[8] Anomalies are characterized by regional departures from an average expressed as standard deviations (SD), calculated by,

$$
S D=\sqrt{\frac{\sum(X-\bar{X})^{2}}{n-1}}
$$

where $n$ is the number of samples ( $\mathrm{n}=34$ for $1979-2012$ and $\mathrm{n}=142$ for 1871-2012). We use a 1979-2006 climatology to facilitate easy comparison with Chase et al. [2008]. Chase et al. [2006] showed through nonparametric estimations of $\mathrm{SD}$, that the relatively small numbers of samples (i.e., in our 1979-2012 cases) have little effect on the anomaly analysis, and we therefore report our results based on the above definition of SD. We compare JJA positive extremes by looking at the percentage of the NHEXT that experienced temperatures exceeding ranges of 2.0, 3.0, and 3.5 SD from the mean climatology. Thus, the term "heat wave" is used in referring to extreme positive temperature anomalies relative to a given locations mean climatology. We acknowledge the data are nonstationary over time; however, we assume normally distributed data for comparison with previous studies [Chase et al., 2000, 2006, 2008]. From this assumption, 95.44\%, $99.73 \%$, and $99.95 \%$ of observations should fall within \pm 2.0 , \pm 3.0 , and $\pm 3.5 \mathrm{SD}$ of the mean, respectively.

\section{Temperature and Specific Humidity Anomalies in the NHEXT}

\subsection{NCEP Positive Anomalies}

[9] In all but one of the past 11 summers, some percentage of the NHEXT experienced temperature anomalies greater than 3.0 SD; however, most of these occurred over less than $2 \%$ (Figure $1 \mathrm{a}$ ) of the analysis region. Summer temperatures exceeded the 3.0 SD threshold only three times prior to this during the period of 1979-2002.

[10] The spatial distribution of temperature and specific humidity anomalies during three highly localized JJA heat waves (2003 near Europe, 2010 over Russia, and 2012 near Greenland) are shown in Figure 2. All three of these cases 
GILL ET AL.: SUMMER TEMP AND HUMIDITY ANOMALIES
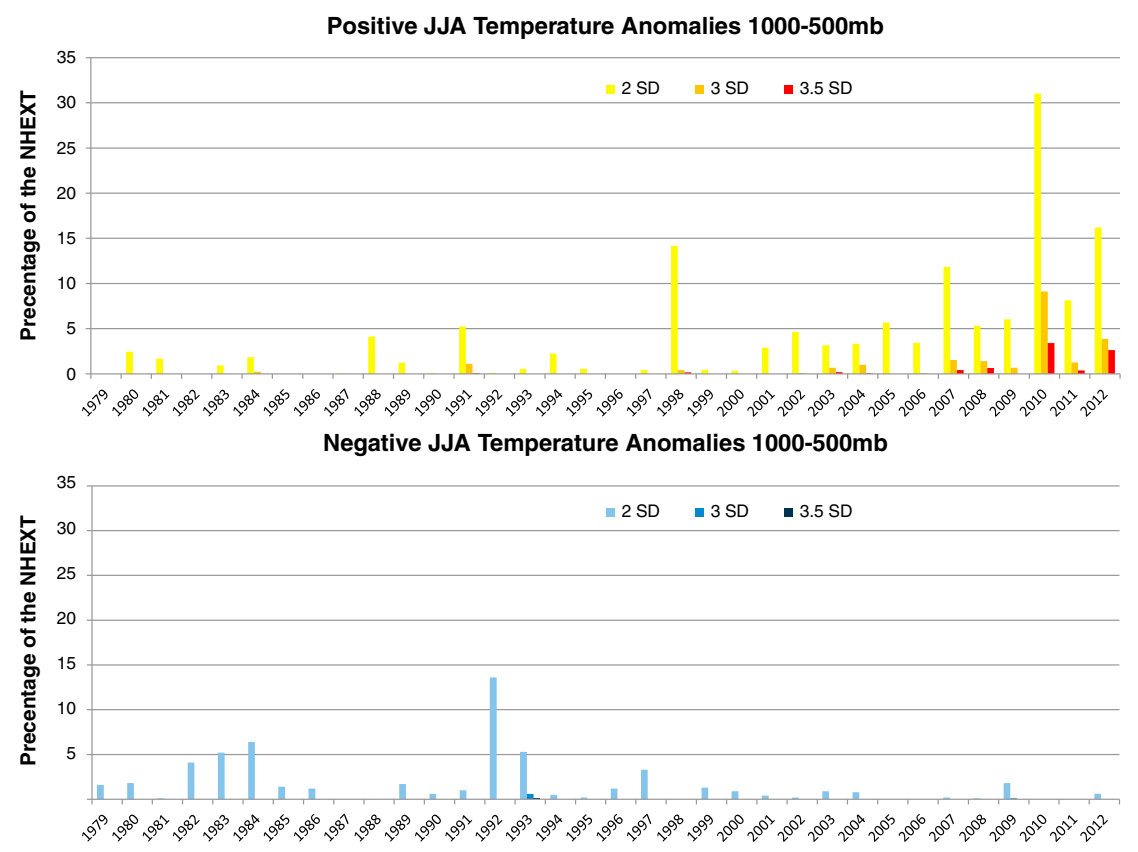

Figure 1. Percentage of the NHEXT $\left(22-80^{\circ} \mathrm{N}\right)$ covered by (a) positive/warm and (b) negative/cold temperature anomalies of 2.0, 3.0, and 3.5 SD levels in JJA since 1979 using the NCEP Reanalysis. Regression analyses were done for both the entire time period (1979-2012) and the overlapping time period (1979-2010) with the $20^{\text {th }}$ century reanalysis; results found in Table 1.

featured average summer temperatures exceeding $3.5 \mathrm{SD}$ of the climatology. In the summer of 2010 , greater than $30 \%$ of the NHEXT experienced positive temperature anomalies exceeding 2.0 SD (Figures 1a and 2). Additionally, about 9\% experienced positive temperature anomalies exceeding 3.0 SD. The summer of 2012 is the second most extreme summer in this record, behind 2010, with almost the same percentage of the NHEXT experiencing temperatures greater than 3.5 SD. While it is accurate to use Figure 1 to compare of spatial extent of the localized heat waves of 2003, 2010, and 2012 (Figure 2), it is important to note that for some of the extreme summers in Figure 1, the "spatial extent," or percentage of the NHEXT, is the summation of small isolated pockets of unusually high temperatures. Chase et al. [2006] linked extreme positive summer temperature anomalies to post-El Niño summers, including in particular 1998, the previous record year for 2.0 SD extent (Figure 1a). While 2010 followed an El Niño winter, it is noteworthy that the summer of 2012 featured such large positive extremes in the wake of a La Niña winter.

[11] The increasing trend in positive temperature anomalies exceeding 2.0 SD (Figure 1a, yellow bars) shows increasing spatial extent of above-average summer temperatures. Furthermore, the increasing trend in the existence of anomalies exceeding both 3.0 SD (Figure 1a, orange bars) and 3.5 SD (Figure 1a, red bars) suggests increasing extremity of summer temperatures. These two findings suggest that the occurrence of extremely high summer temperatures are not only increasing in intensity but are also occurring over a larger percentage of the Northern Hemisphere.

[12] We see a similar pattern of increasing spatial extent and magnitude (Figure 3a) for positive specific humidity anomalies.

Table 1. Regression Results for JJA Temperature Extremes in the NCEP and $20^{\text {th }}$ Century Reanalyses

\begin{tabular}{|c|c|c|c|c|c|c|c|}
\hline & & & Number of Occurrences & Slope $(\% / y r)$ & Intercept $(\%)$ & $\mathrm{R}^{2}$ & $\mathrm{p}$-Value \\
\hline \multirow[t]{6}{*}{ NCEP reanalysis } & \multirow[t]{3}{*}{$(1979-2012)$} & $+2.0 \mathrm{SD}$ & 29 of 34 years & 0.37 & -2.3 & 0.33 & $4.8 \mathrm{E}-4$ \\
\hline & & $+3.0 \mathrm{SD}$ & 13 of 34 years & 0.086 & -0.80 & 0.24 & 0.0041 \\
\hline & & $-2.0 \mathrm{SD}$ & 28 of 34 years & -0.096 & 3.20 & 0.12 & 0.058 \\
\hline & \multirow[t]{3}{*}{$(1979-2010)$} & $+2.0 \mathrm{SD}$ & 27 of 32 years & 0.33 & -1.95 & 0.26 & 0.0031 \\
\hline & & $+3.0 \mathrm{SD}$ & 11 of 32 years & 0.074 & -0.71 & 0.18 & 0.017 \\
\hline & & $-2.0 \mathrm{SD}$ & 27 of 32 years & -0.088 & 3.20 & 0.10 & 0.079 \\
\hline \multirow[t]{8}{*}{$20^{\text {th }}$ century reanalysis } & \multirow[t]{6}{*}{$(1871-2010)$} & $+2.0 \mathrm{SD}$ & 97 of 140 years & 0.0009 & 1.04 & $2.2 \mathrm{E}-4$ & 0.86 \\
\hline & & $+3.0 \mathrm{SD}$ & 30 of 140 years & -0.0005 & 0.18 & $2.7 \mathrm{E}-3$ & 0.54 \\
\hline & & $+3.5 \mathrm{SD}$ & 13 of 140 years & -0.0003 & 0.073 & $2.5 \mathrm{E}-3$ & 0.55 \\
\hline & & $-2.0 \mathrm{SD}$ & 127 of 140 years & -0.049 & 8.44 & 0.20 & $3.1 \mathrm{E}-8$ \\
\hline & & $-3.0 \mathrm{SD}$ & 104 of 140 years & -0.024 & 3.12 & 0.20 & $3.2 \mathrm{E}-8$ \\
\hline & & $-3.5 \mathrm{SD}$ & 90 of 140 years & -0.016 & 1.86 & 0.14 & $6.9 \mathrm{E}-6$ \\
\hline & \multirow[t]{2}{*}{$(1979-2010)$} & $+2.0 \mathrm{SD}$ & 22 of 32 years & 0.12 & -0.56 & 0.33 & $6.9 \mathrm{E}-4$ \\
\hline & & $-2.0 \mathrm{SD}$ & 19 of 32 years & -0.055 & 1.92 & 0.094 & 0.094 \\
\hline
\end{tabular}



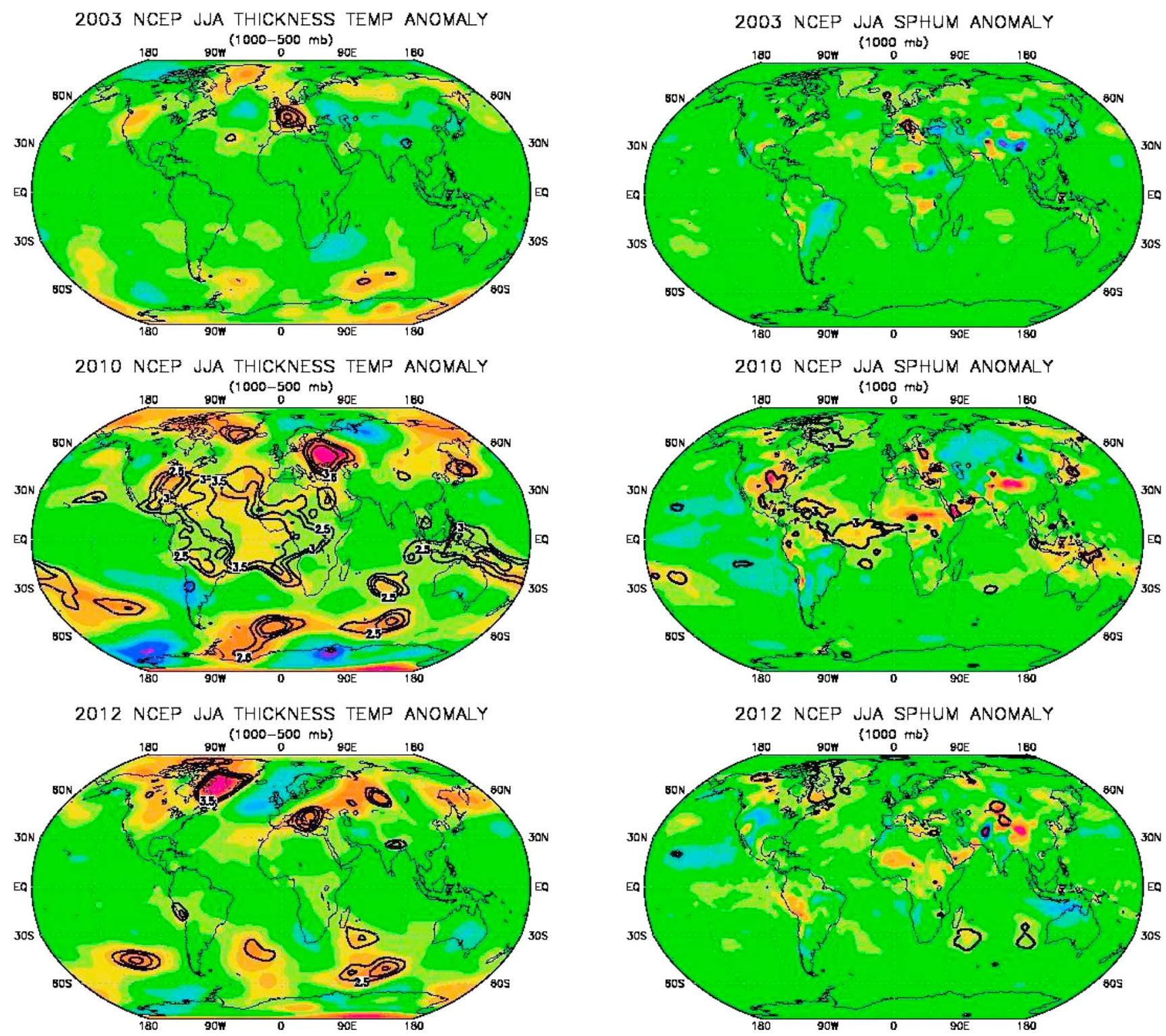

Specifically, each of the past six years experienced positive specific humidity anomalies exceeding $3.5 \mathrm{SD}$ and 9 of the past 11 summers experienced anomalies exceeding 3.0 SD.

[13] Given interest over warming of the atmosphere in general, the same analysis was performed for winter months (December, January, and February, DJF) for comparison. We see that there is a significant increase in the percentage of the northern hemisphere experiencing above-average winter temperatures at the 2.0 SD level (Figure 4a). Extremes above this level (3.0 and 3.5 SD) only occurred a handful of times during DJF 2009-2012. Note the definition of a winter year, here, includes December of the previous year (i.e., DJF 2009 is December 2008, January 2009, and Feb 2009).

\subsection{NCEP Negative Anomalies}

[14] Cold temperature anomalies appear to exhibit an opposite trend: occurring with less frequency and magnitude over smaller spatial extents. The only year with cold summer anomalies below 3.0 SD was 1993 (Figure 1b), most likely associated with lingering effects from the $1991 \mathrm{Mt}$. Pinatubo eruption. Interestingly, of the past 15 consecutive summers, only $2 \%$ or less of the NHEXT region experienced negative summer temperature anomalies. Prior to this, relatively significant $(-2.0 \mathrm{SD})$ negative summer temperature anomalies existed (1982, 1983, 1984, 1992, and 1993). These findings show a decreasing trend in negative summer temperature anomalies in the NHEXT. 
GILL ET AL.: SUMMER TEMP AND HUMIDITY ANOMALIES

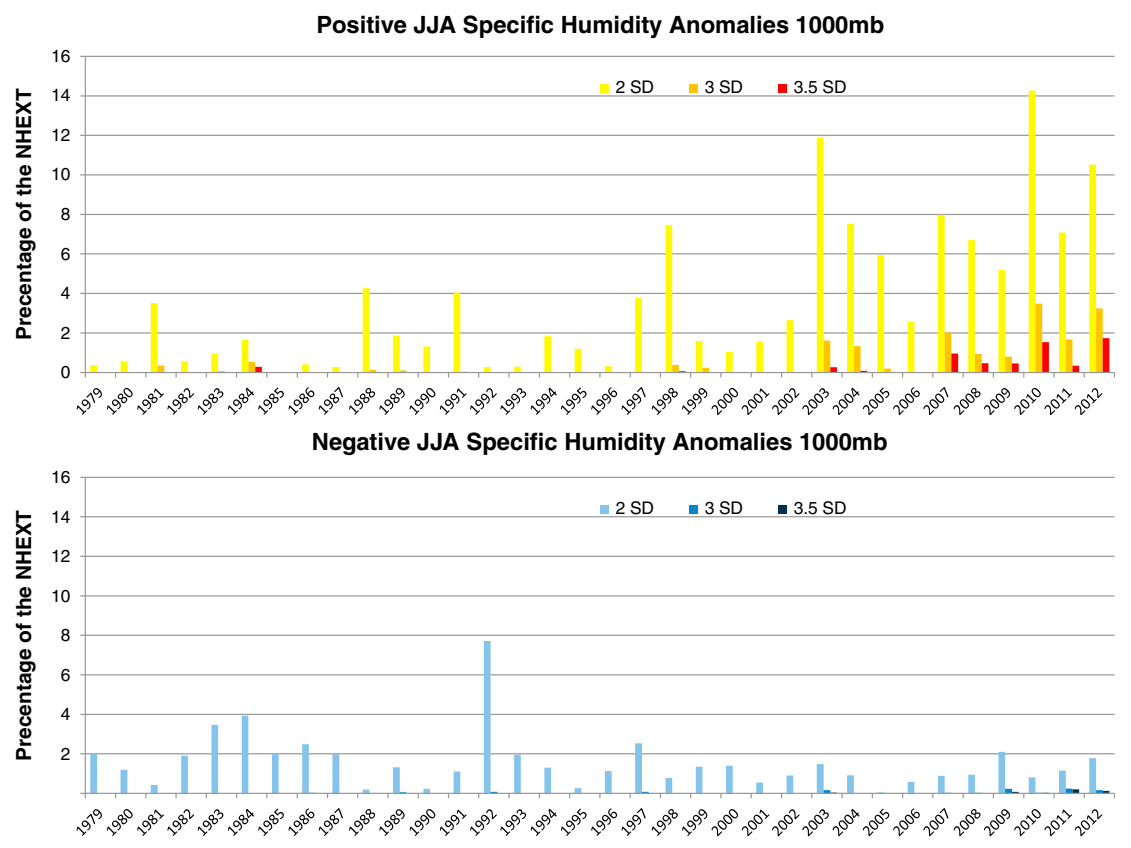

Figure 3. Percentage of the NCEP NHEXT $\left(22-80^{\circ} \mathrm{N}\right)$ covered by (a) positive and (b) negative specific humidity anomalies of 2.0, 3.0, and 3.5 SD levels in JJA since 1979. Regression analysis results for specific humidity anomalies exceeding $+2.0 \mathrm{SD}$ (occurred in 33 of 34 years): slope $=0.27 \% / \mathrm{yr}$, intercept $=-0.24 \%$, $\mathrm{R}^{2}=0.48, \mathrm{p}$-value $=8.4 \mathrm{E}-6$. Regression analysis results for specific humidity anomalies exceeding +3.0 $\mathrm{SD}$ (occurred in 13 of 34 years): slope $=0.060 \% / \mathrm{yr}$, intercept $=-0.50 \%, \mathrm{R}^{2}=0.40$, $\mathrm{p}$-value $=7.8 \mathrm{E}-5$. Regression analysis results for specific humidity anomalies exceeding +3.5 SD (occurred in 9 of 34 years): slope $=0.025 \% / y r$, intercept $=-0.96 \%, \mathrm{R}^{2}=0.33, \mathrm{p}$-value $=0.0050$. Regression analysis results for specific humidity anomalies under $-2.0 \mathrm{SD}$ (occurred in 28 of 34 years): slope $=-0.039 \% / \mathrm{yr}$, intercept $=$ $2.2 \%, \mathrm{R}^{2}=0.069, \mathrm{p}$-value $=0.14$.

[15] Similarly, few summers experienced negative specific humidity anomalies exceeding 3.0 SD (Figure 3b). In fact, it appears the spatial extent of extreme negative specific humidity events of 2.0 SD during the summer has diminished over the past twenty years.

[16] Extreme cold events during the winter months (Figure 4b) have remained fairly constant (possibly a slight decline) throughout the 1979-2012 time period at the 2.0 SD level.

\subsection{Correlation Between NCEP Temperature and Specific Humidity Anomalies}

[17] For each sigma level (SD), the percent area of NHEXT experiencing positive temperature anomalies was found to be correlated in a Pearson's test with the percent area of NHEXT experiencing positive specific humidity anomalies (for $2.0 \mathrm{SD}$, $r=0.74, \mathrm{p}=8.3 \mathrm{E}-7$; for $3.0 \mathrm{SD}, r=0.86, \mathrm{p}=5.4 \mathrm{E}-11$; for 3.5 SD, $r=0.73, \mathrm{p}=1.1 \mathrm{E}-6)$, suggesting that JJA summers experiencing extremely warm temperatures most likely experienced positive specific humidity anomalies.

[18] NHEXT JJA spatial correlations between temperature and specific humidity were calculated for each year and always fell between 0.61 and 0.70 , showing correlation between regions of the NHEXT experiencing both temperature and specific humidity anomalies in a given summer.

[19] From the previous correlations, we find that summers experiencing positive temperature anomalies were also experiencing positive specific humidity anomalies and that these correlations are mostly happening over similar regions within the NHEXT. To determine whether there is any predictable temporal variation between these extremes, we performed lag correlations on a seasonal and monthly time scale. For instance, we investigated whether the positive temperature (temp) anomaly averaged from March, April, and May (MAM) was spatially correlated with the JJA anomalies of average specific humidity (shum). We ran the following lag correlations: (1) MAM temp with JJA shum, (2) MAM shum with JJA temp, (3) May temp with June shum, (4) May shum with June temp, (5) June temp with July shum, (6) June shum with July temp, (7) July shum with August temp, and (8) July temp with August shum. In each case, correlations were weak or inconsistent, showing no evidence that unusually high specific humidity levels cause unusually high temperatures (or vice versa) on a seasonal or monthly scale. Pfahl and Niedermann [2011] find very strong daily covariation between humidity and temperature, suggesting the time scale of this analysis was too broad.

\subsection{Comparison of NCEP Temperature Anomalies With $20^{\text {th }}$ Century Reanalysis Temperature Anomalies}

[20] While the anomaly analysis performed using the $20^{\text {th }}$ century reanalysis data revealed similar overall trends in temperature anomalies (increasing positive anomalies and decreasing negative anomalies) across the overlapping 1979-2010 time period (Figure 5), there were also some noteworthy differences. First, the $20^{\text {th }}$ century reanalysis revealed positive temperature anomalies during the earlier part of the time series (not covered by NCEP) that rival the magnitude 
GILL ET AL.: SUMMER TEMP AND HUMIDITY ANOMALIES

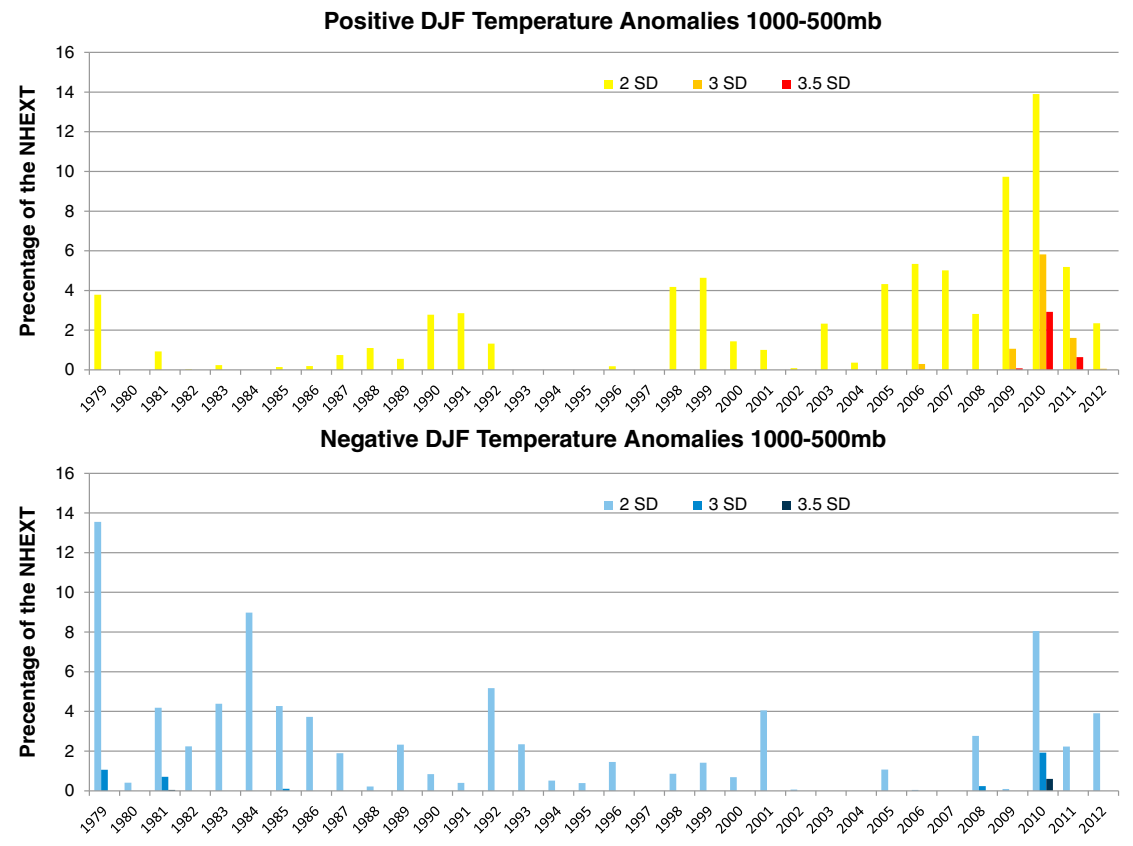

Figure 4. Percentage of the NCEP NHEXT $\left(22-80^{\circ} \mathrm{N}\right)$ covered by (a) positive and (b) negative temperature anomalies of 2.0, 3.0, and 3.5 SD levels in DJF since 1979. Regression analysis results for temperatures exceeding +2.0 SD (occurred in 28 of 34 years): slope $=0.17 \% / \mathrm{yr}$, intercept $=-0.76 \%, \mathrm{R}^{2}=0.32$, $\mathrm{p}$-value $=4.6 \mathrm{E}-4$. Regression analysis results for temperature anomalies under $-2.0 \mathrm{SD}$ (occurred in 30 of 34 years): slope $=-0.10 \% / \mathrm{yr}$, intercept $=4.2 \%, \mathrm{R}^{2}=0.11, \mathrm{p}$-value $=0.05$. Note that the DJF 2012 refers to the average of December 2011 and January and February 2012.
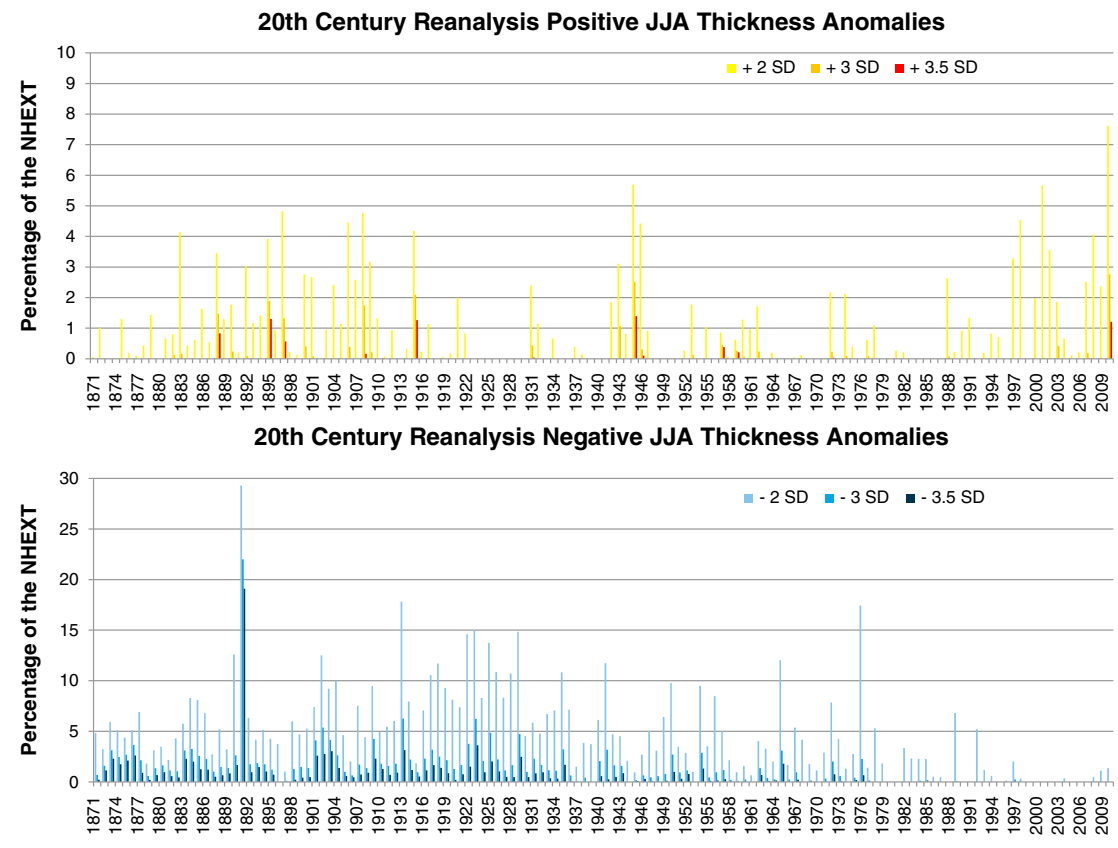

Figure 5. Percentage of the NHEXT $\left(22-80^{\circ} \mathrm{N}\right)$ covered by (a) positive/warm and (b) negative/cold temperature anomalies of 2.0, 3.0, and 3.5 SD levels in JJA since 1871 using the $20^{\text {th }}$ century reanalysis. Regression analyses were done for both the entire time period (1871-2010) and the overlapping time period (1979-2010) with the NCEP Reanalysis; results found in Table 1. Note the change in the range of the ordinate axes between Figures $4 \mathrm{a}$ and $4 \mathrm{~b}$. 

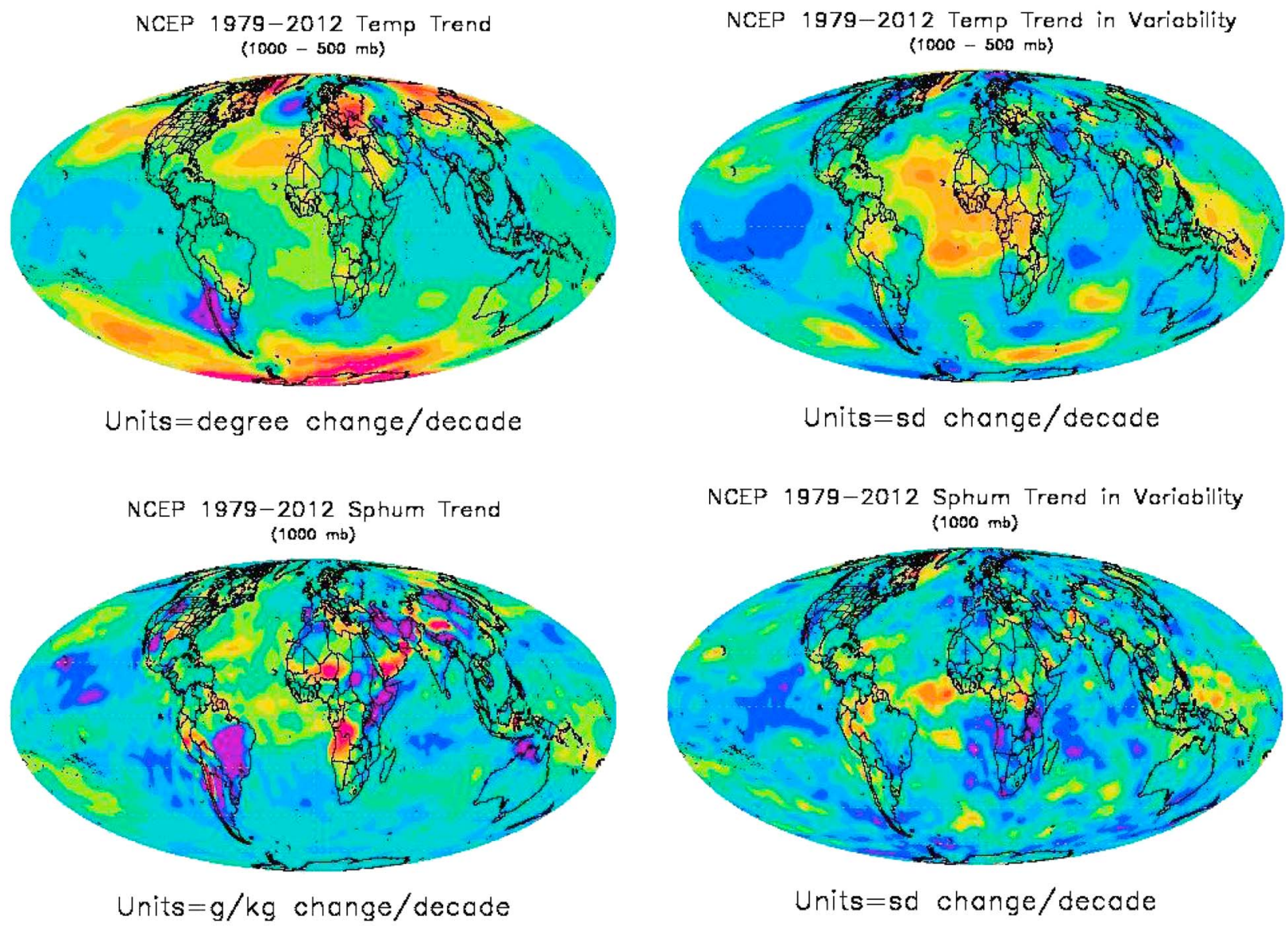

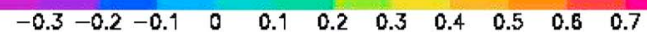

Figure 6. NCEP reanalysis spatial global temperature trends in (a) degree Kelvin per decade and (b) SD change per decade and specific humidity trends in (c) g/kg per decade and (d) SD change per decade.

and spatial extent of positive anomalies in the past decade. Furthermore, in general, across the 1871-2010 time period, $+2 \mathrm{SD}$ anomalies in temperature never extended beyond $10 \%$ of the NHEXT, which is significantly smaller than seen in the NCEP analysis. Our results support those of Peterson et al. [2013], who found that the highest number of cold waves was found in the 1980s and the lowest in the 2000s. Furthermore, their results place ours in a longer context: the highest number of heat waves occurred in the 1930s, the second highest number of heat waves occurred in the 2000s, and the fewest number of heat waves occurred in the 1960s [Peterson et al., 2013; see Figure 1].

\section{Trends in Variability}

[21] We calculated the NCEP linear trend in temperature $(\Delta$ Kelvin/decade; Figure $6 \mathrm{a})$, temperature variability $(\Delta \mathrm{SD} /$ decade; Figure $6 \mathrm{~b})$, specific humidity $(\Delta \mathrm{g} / \mathrm{kg} / \mathrm{decade}$; Figure $6 \mathrm{c})$, and specific humidity variability $(\Delta \mathrm{SD} /$ decade; Figure 6d) over the 1979-2012 time span of temperature reported as degree Kelvin per decade and SD change per decade, respectively. Both temperature and specific humidity show similar regional patterns in variability. For instance, there is an oscillation between areas with increasing variability and areas with decreasing variability along the $60-80^{\circ} \mathrm{N}$ latitudes. There was increased variability near Greenland and decreased variability north of Siberia, possibly associated with an extreme retreat of sea ice in the first region, but not for the second region. Furthermore, both temperature and specific humidity show areas experiencing significantly positive trends of variability along the equatorial Atlantic region and east of the Philippines of up to $+0.6 \mathrm{SD} /$ decade trends.

[22] Interestingly, the areas that have experienced the most extreme heat waves since 1979 (Figure 6b) fall outside of areas of substantially increasing or decreasing variability trends. To quantify this, we spatially correlated the temperature anomalies for years of extreme localized heat waves $(1998,2003,2008,2010$, and 2012) with the global trend in variability. In chronological order the global spatial correlations were $0.07,0.01,0.31,0.41$, and 0.34 , which shows that areas of localized heat waves are typically not areas that experience the most change in variability. It is worth mentioning, however, that the area of the JJA heat wave this past summer off the coast of Greenland (Figure 2) falls within an area of increasing temperature variability (Figure 6b). This is an indication that localized heat waves are, at most, only 
weakly related to global trends, adding support to the conclusions of Dole et al. [2011] that circulation pattern changes dominate the explanation for the trends.

\section{Conclusions}

[23] This study compared temperature and specific humidity anomalies since 1979 in the NCEP/NCAR global reanalysis in the NHEXT region. We also compared overlapping time series of NCEP and $20^{\text {th }}$ century reanalysis for temperature anomalies, finding similar patterns of increasing positive temperature anomalies and decreasing negative temperature anomalies from 1979 to 2010. According to the NCEP/ NCAR global reanalysis, summer heat waves are increasing in frequency, magnitude, and spatial scale and are generally accompanied by positive specific humidity anomalies. These findings are consistent with theories surrounding the positive water vapor feedback cycle although at the regional scale. The spatial scale of negative summer temperature and specific humidity anomalies are relatively small, and they have been less prevalent in the past decade.

[24] We also find the following: (1) winter months show an increase in the percentage of northern hemisphere experiencing +2.0 SD temperatures but barely any decrease in extreme cold winter events; (2) there is a correlation between summers and regions experiencing extremes in temperature and specific humidity; (3) lag correlations show that specific humidity anomalies are not preceding temperature extremes on a monthly or seasonal time scale; and (4) with the exception of Greenland in 2012, temperature extremes are not necessarily occurring in areas of increased global variability.

[25] Heat waves and specific humidity anomalies vary together in time (consistent with Cripe and Randall, [2001]) and generally occur over the same region. Since lag correlations on a monthly time scale did not reveal significant relationships between temperature and specific humidity, future research may benefit from looking at heat waves on a shorter temporal scale such as weekly, as well as assessing the combined effect of temperature and water vapor using lower tropospheric moist enthalpy as the metric [e.g., see Fall et al., 2010].

[26] Finally, the areas where temperature is increasing and decreasing in variability are the same areas where specific humidity is increasing and decreasing in variability. For example, areas that are becoming more variable in temperature are also becoming more variable in specific humidity, and vice versa. However, these are not the areas that are necessarily experiencing heat waves. While this suggests that the spatial distribution of heat waves may be dominated by circulation, this study did not attempt to explain the increase in the extremity of heat waves.

[27] Being that the NCEP/NCAR GR combines modeled and observed data, it makes sense both theoretically and practically that temperature and specific humidity anomalies would be correlated within this data set. Future research would benefit from looking at these relationships across other data sets. Simmons et al. [2010] compared trends in atmospheric humidity, temperature, and precipitation across multiple reanalyses, including European Center for Medium-Range Weather Forecasts ERA-40 and ERA-Interim and the Climate Research Unit and Hadley Centre CRUTEM3. In 10 year comparisons between 1979-1988 and 1999-2008, both CRUTEM3 and ERA show a significant increase in positive temperature anomalies across the northern hemisphere, particularly Europe, North America, and Greenland. Our findings in the NCEP/NCAR reanalysis support the findings of Simmons et al. [2010].

[28] Interestingly, Simmons et al. [2010] found a decrease in relative humidity from about 1999 to 2008. For the previous 30 years, relatively humidity remained relatively stable, as most literature predicts, as specific humidity increased with increasing temperatures. Given increases in temperature over the past decade, a decline in relative humidity suggests that specific humidity is either staying the same or decreasing. It is therefore noteworthy that our results show robust positive trends in specific humidity anomalies over this same time period.

[29] Furthermore, we plan to investigate anomalies in other factors that have been discussed to affect the prevalence of heat waves, including soil moisture, above ground biomass, incident surface short- and long-wave radiation, and precipitation, as well as changes in time of major circulation features. We are also analyzing changes in extremes for other seasons of the year, and for the Southern Hemisphere.

[30] Acknowledgments. We thank the University of Colorado's Cooperative Institute for Research in Environmental Science, Dr. Balaji Rajagopalan, and Alex Robershotte for their contributions and support in this project. Thank you to Gilbert Compo and Chesley McColl at NOAA's ESRL Physical Sciences Division for your assistance with the 20th Century reanalysis. We also thank the Integrated Teaching and Learning Program under the National Science Foundation GK-12 grant 0946502 as well as the University of Colorado's Department of Civil, Environmental, and Architectural Engineering for funding during this project. Roger Pielke Sr. also received support from NSF Project AGS 1219833.

\section{References}

Allen, M. R., and W. J. Ingram (2002), Constraints on future changes in climate and the hydrologic cycle, Nature, 419, 224-232.

Barriopedro, D., E. M. Rischer, J. Luterbacher, R. M. Trigo, and R. Garcia-Herrera (2011), The hot summer of 2010: Redrawing the temperature record map of Europe, Science, 332, 220-224.

Chase, T. N., R. A. Pielke, J. A. Knaff, T. G. F. Kittel, and J. L. Eastman (2000), A comparison of regional trends in 1979-1997 depth-averaged tropospheric temperatures, Int. J. Climatol., 20, 503-518.

Chase, T. N., K. Wolter, R. A. Pielke, Sr., and I. Rasool (2006), Was the 2003 european summer heat wave unusually in a global context?, Geophys. Res. Lett., 33, L23709, doi:10.1029/2006GL027470.

Chase, T. N., K. Wolter, R. A. Pielke, Sr., and I. Rasool (2008), Reply to comment by W. M. Connolley on "Was the 2003 European summer heat wave unusual in a global context?", Geophys. Res. Lett., 35, L02704, doi:10.1029/2007GL031574.

Compo, G. P., et al. (2011), The twentieth century reanalysis project, Quart J. Roy. Metrol. Soc., 137, 1-28, doi:10/1002/qj.776.

Cripe, D. G., and D. A. Randall (2001), Joint variations of temperature and water vapor over the midlatitude continents, Geophys. Res. Lett., 28, 2,613-2,616.

Dessler, A. E., and S. M. Davis (2010), Trends in tropospheric humidity from reanalysis systems, J. Geophys. Res., 115, D19127, doi:10.1029/ 2010JD014192.

Dessler, A. E., and S. C. Sherwood (2009), A matter of humidity, Science, $323,1,020-1,021$

Dole, R., M. Hoerling, J. Perlwitz, J. Eischeid, P. Pegion, T. Zhang, X.-W. Quan, T. Xu, and D. Murray (2011), Was there a basis for anticipating the 2010 Russian heat wave?, Geophys. Res. Lett., 38, L06702, doi:10.1029/2010GL046582.

Donat, M. G., and L. V. Alexander (2012), The shifting probability distribution of global daytime and night-time temperatures, Geophys. Res. Lett., 39, L14707, doi:10.1029/2012GL052459.

Durack, P. J., S. E. Wijffels, and R. J. Matear (2012), Ocean salinities reveal strong global water cycle intensification during 1950 to 2000, Science, $336,455-458$

Emori, S., and S. J. Brown (2005), Dynamic and thermodynamic changes in mean and extreme precipitation under climate change, Geophys. Res. Lett., 32, L17706, doi:10.1029/2005GL023272. 


\section{GILL ET AL.: SUMMER TEMP AND HUMIDITY ANOMALIES}

Fall, S., N. Diffenbaugh, D. Niyogi, R. A. Sr.Pielke, and G. Rochon (2010), Temperature and equivalent temperature over the United States $(1979-2005)$, Int. J. Climatol., doi:10.1002/joc.2094.

Held, I. M., and B. J. Soden (2000), Water vapor feedback and global warming, Annu. Rev. Energy Environ., 25, 441-475.

Held, I. M., and B. J. Soden (2006), Robust responses of the hydrological cycle to global warming, J. Climatol., 19, 5,686-5,699.

Kalnay, E., et al. (1996), The NCEP/NCAR 40-year reanalysis project, Bull. Am. Meteorol. Soc., 77, 437-470.

Khon, V. C., W. Park, M. Latif, I. I. Mokhov, and B. Schneider (2010), Response of the hydrological cycle to orbital and greenhouse gas forcing, Geophys. Res. Lett., 37, L19705, doi:10.1029/2010GL044377.

Paltridge, G., A. Arking, and M. Pook (2009), Trends in middle- and upperlevel tropospheric humidity from NCEP reanalysis data, Theor. Appl. Climatol., 98, 351-359.

Peterson, T. C., et al. (2013), Monitoring and understanding changes in heat waves, cold waves, floods and droughts in the United States: State of knowledge, Bull. Am. Meteorol. Soc., doi:10.1175/BAMS-D12-00066.1.

Pfahl, S., and N. Niedermann (2011), Daily covariation in near-surface relative humidity and temperature over the ocean, J. Geophys. Res., 116, D19104, doi:10.1029/2011JD015792.

Rahmstorf, S., and D. Coumou (2011), Increase of extreme events in a warming world, Proc. Nat. Acad. Sci., 108, doi:10.1073/pnas.1101766108.

Randall, D. A., et al. (2007), Climate models and their evaluation, in Climate Change 2007: The Physical Science Basis. Contributions of Working Group I to the Fourth Assessment Report of the Intergovernmental Panel on Climate Change, edited by S. Solomon et al., pp. 591-662, Cambridge University Press, Cambridge, U.K.
Santer, B. D., et al. (2007), Identification of human-induced changes in atmospheric moisture content, Proc. Natl. Acad. Sci., 104(39), doi:10.1073/ pnas.0702872104

Schmidt, G. A., R. A. Ruedy, R. L. Miller, and A. A. Lacis (2010), Attribution of the present-date total greenhouse effect, J. Geophys. Res. 115, D20106, doi:10.1029/2010JD014287.

Schneider, E. K., B. P. Kirtman, and R. S. Lindzen (1999), Tropospheric water vapor and climate sensitivity, J. Atmos. Sci., 56, 1,649-1,658.

Simmons, A. J., K. M. Willett, P. D. Jones, P. W. Thorne, and D. P. Dee (2010), Low-frequency variations in surface atmospheric humidity, temperature, and precipitation: Inferences from reanalyses and monthly gridded observational data sets, J. Geophys. Res., 115, D01110, doi:10.1029/2009JD012442.

Sun, D.-Z., Y. Yu, and T. Zhang (2009), Tropical water vapor and cloud feedbacks in climate models: A further assessment using coupled simulations, J. Climate, 22, 1,287-1,304.

Trenberth, K. E. (1998), Atmospheric moisture residence times and cycling: Implications for rainfall rates and climate change, Clim. Change, 39 667-694.

Trenberth, K. E. (1999), Conceptual framework for changes of extremes of the hydrological cycle with climate change, Clim. Change, 42, 327-339.

Vonder Haar, T. H., J. L. Bytheway, and J. M. Forsythe (2012), Weather and climate analyses using improved global water vapor observations, Geophys. Res. Lett., 39, L15802, doi:10.1029/2012GL052094.

Wentz, F. J., L. Ricciardulli, K. Hilburn, and C. Mears (2007), How much more rain will global warming bring?, Science, 317, 233-235.

Willett, K. M., N. P. Gillett, P. D. Jones, and P. W. Thorne (2007), Attribution of observed surface humidity changes to human influence, Nature, 449, 710-712. 